\title{
Strategy for rheumatology: hospital versus community
}

How can our system of providing rheumatological services be made more effective and more efficient? The answer to this question entails careful consideration of five issues: $(a)$ the health burden posed by rheumatic diseases, $(b)$ the services currently provided by the specialty, $(c)$ measurement of the shortfalls between need and provision, $(d)$ evaluating alternative strategies of provision, and $(e)$ incorporating successful strategies into the altered structural framework which has recently been laid down for the health service as a whole. Although much more information is required about each of these five issues before the question posed above can be fully answered, some inroads have been made recently.

\section{Rheumatological health burden}

The spectrum of rheumatic diseases is extremely diverse, and they are among the most widespread painful conditions to which the population of this country is subject. ${ }^{1}$ Estimates suggest that $16 \%$ of all men and women consult their general practitioner for a locomotor disorder during the course of any single year. ${ }^{2}$ These conditions are, in addition, a major cause of disability in Britain $^{3}$ and consume a large proportion of health service budgets. Increasing awareness of these conditions, better management, a more demanding public, and an older population are all conspiring to increase the burden and importance of this branch of medicine.

Population based epidemiological data are available for some rheumatic disorders. The prevalence of rheumatoid arthritis in women rises from around $1 \%$ during the third and fourth decades of life, to $5 \%$ in those aged 75 years and above. ${ }^{4}$ The prevalence in men is around half that in women at all ages. Osteoarthritis has a higher prevalence. Medically confirmed signs and symptoms of osteoarthritis are present in about $12 \%$ of the adult population of the United States (all ages). ${ }^{5}$ Symptomatic knee osteoarthritis together with radiological evidence of the disease is present in about five million United States citizens, ${ }^{5}$ and radiological knee osteoarthritis occurs with rates of $18 \%$ and $17 \%$ in samples of men and women respectively aged 75 to 84 years. ${ }^{6}$ The incidence of these two conditions, however, has been far more difficult to measure precisely. Incidence rates for rheumatoid arthritis derived in the last two decades from two United States population samples have differed appreciably. ${ }^{7}$ The incidence of osteoarthritis at various joint sites remains unknown, as does the descriptive epidemiology of many soft tissue rheumatic disorders, and the less commonly seen connective tissue disorders and arthritides.

\section{Provision of current services}

Current provision for these conditions is two tiered. Much rheumatology is catered for by general practitioners with varying levels of expertise in the specialty. This is supplemented by a hospital based cadre of around 250 consultants and 75 senior registrars in rheumatology. Most hospital based rheumatology treatment takes place in outpatient departments. Inpatient beds are used infrequently for the management of severe rheumatic diseases. There is considerable overlap in hospitals between rheumatological, orthopaedic, and general medical services. In addition, adequate management of the disability stemming from rheumatic diseases requires close liaison in hospital between rheumatology and paramedical specialties_most notably, physiotherapy, occupational therapy, and social services.

Characterisation of the current rheumatological service in the South Western Regional Health Authority suggested a workload dominated by rheumatoid arthritis_-inflammatory polyarthritis accounted for $43 \%$ of new outpatient referrals and $76 \%$ of follow up consultations (Kirwan and Snow, unpublished data). Rheumatologists in this region saw little soft tissue rheumatism and back problems (perhaps $1 \%$ of all new cases), in contrast with the experience of other regions of the country. ${ }^{8}$ Waiting times for new outpatient appointments were found to be substantial and wide variation existed in the follow up practices of individual rheumatologists.

\section{Shortfall between need and provision}

Extrapolation from these data suggests that around 50-60\% of new cases of rheumatoid disease are referred for rheumatological consultation, as compared with a tiny proportion of cases of osteoarthritis or soft tissue rheumatism. This provision functions adequately in the present setting where disproportionately large amounts of outpatient (and especially inpatient) time and resources are devoted to a small number of patients with severe or systemic rheumatoid arthritis and the rarer connective tissue diseases, and where treatment regimens which require detailed, regular follow up are more restricted to patients with rheumatoid arthritis who are receiving second line drugs. Our understanding of the pathological basis of osteoarthritis has grown enormously in recent years, however, and the possibility that disease modifying treatments will emerge in the near future has become a real one. ${ }^{9}$ Furthermore, complete management of osteoarthritis and many soft tissue rheumatic disorders includes many of the paramedical services which are currently hospital based, as well as doctors who at the very least are acquainted with their clinical features and nonsurgical management.

\section{Strategies of provision}

Alternative strategies to the current hospital based rheumatology service are worthy of consideration. Most radical among these is a shift of service provision from hospital to community. Many clinicians will have been presented with organisational proposals from district and regional health authorities in which the decision to develop 'community hospitals' has been written into strategic plans for the next decade or so. Such hospitals, of $20-40$ beds, would be serviced by local general practitioners and would provide inpatient facilities for up to $20 \%$ of patients who did not require 'high technology' medicine. It is difficult to see how rheumatology can contribute $20 \%$ of its inpatient facilities to such a system when our patients are usually admitted either for intensive medical investigation and care, or for specialist remedial and rehabilitation services which depend 
upon a well coordinated and skilled team of medical and paramedical staff. These facilities are difficult enough to draw together in a district general hospital, let alone a small, general practitioner based unit. Despite the possibility that rheumatology may not be a core specialty in the new health service it is unlikely that the discipline will find it possible, or desirable, to sever its links with hospital medicine.

An intermediate approach might be to increase the sessional commitment to clinics based in the community. Such use of peripatetic care has been evaluated and found useful in other chronic disease specialties, such as diabetology. ${ }^{10}$ Community based consultant sessions might be used to support 'specialist' general practitioners, who would be able to liaise closely with the rheumatology department, as well as to provide local outpatient clinics. Balanced against the advantages, however, are the potential loss of time spent travelling and administering such a system and the effects of removing consultant cover from the hospital base. Perhaps telephone or even video links might help to avoid these problems.

Another dimension of rheumatological practice which has begun to receive attention is the educational role of the hospital based rheumatologist. Examination of general practitioner referrals to rheumatologists in Leicester ${ }^{11}$ showed wide variation in the referral rates of individual practitioners. Such data suggest that auditing of referral practices might enable identification of groups of general practitioners who would benefit from rheumatological education. A study of referral practices within Bristol, however, suggested that the vast majority of general practitioners referred patients appropriately (Stellakis $e t a l$, unpublished data). On this basis, an educational strategy targetted at the whole population of general practitioners seems more prudent. Clearly, referral patterns within small areas are prone to considerable geographical variation. ${ }^{12}$ Determination of appropriate educational strategies will inevitably entail research into these local circumstances.

\section{Incorporating strategies in the NHS}

In conclusion, rheumatic disorders constitute a major financial and health burden for the British population. The present provision for these disorders seems to fall short of the demand for them. We urgently need to measure this shortfall and consider alternative methods for the delivery of rheumatological care, both within the hospital system and the community.

The changes proposed in the government white paper ${ }^{13}$ will always impose a financial drive towards community based care for chronic illnesses and disability. ${ }^{14}$ It is imperative that rheumatologists consider the available options in a constructive and wholehearted manner. We shall have to measure the clinical benefit or loss which patients accrue in relation to proposed or actual changes in the provision or organisation of rheumatological care, and to advocate those which are shown to be therapeutically preferrable. If we do not, working practices which are not palatable may well be forced upon us from without.

Rheumatology Unit,

University Department of Medicine,

Bristol Royal Infirmary,

Bristol BS2 8HW

1 Wood P H N, ed. The challenge of arthritis and rheumatism. A report on problems and progress in health care for rheumatic disorders. London: British League against Rheumatism, 1977.

2 District Rheumatology Services. A report on the committee on rheumatology of the Royal College of Physicians of London. Br $\mathcal{F}$ Rheumatol 1988; 27: $54-61$.

3 Wood P H N. The changing spectrum of disability: the increasing burden of arthritis. Rehabilitation 1973; 84: 5-11.

4 Linos A, Worthington J W, O'Fallon W M, Kurland L T. The epidemiology of rheumatoid arthritis in Rochester, Minnesota: a study of incidence, prevalence and mortality. Am $\mathcal{F}$ Epidemiol 1980; 111: 87-98.

5 Lawrence R C, Hochberg M C, Kelsey J L, et al. Estimates of the prevalence of selected arthritis and musculoskeletal disease in the United States. f Rheumatol 1989; 16: 427-41.

6 Felson D T, Naimark A, Anderson J, Kazis L, Castelli W, Meenan R F. The prevalence of knee osteoarthritis in the elderly. The Framingham osteoprevalence of knee osteoarthritis in the elderly.
arthritis study. Arthritis Rheum 1987; 30: 914-8.

7 Dugowson C E, Bley L, Koepsell T D, Nelson J L, Daling J R. Incidence of Dugowson C E, Bley L, Koepsell T D, Nelson J L, Daling J R. Incidence of
rheumatoid arthritis in women [Abstract]. Arthritis Rheum 1989; 32: S63. rheumatoid arthritis in women [Abstract]. Arthritis Rheum 1989; 32: S63.
Bamji A, Dieppe P A, Hasloch I, Shipley M. What do rheumatologists do? A pilot audit study [Abstract]. Br f Rheumatol 1987; 26 (suppl 1): 56-7.

9 Doherty $M$. 'Chondroprotection' by non-steroidal anti-inflammatory drugs. Ann Rheum Dis 1989; 48: 619-21.

10 Home P, Walford S. Diabetes care. Whose responsibility? Br Med J 1984; 289: $713-4$.

11 Samanta A, Roy S. Referrals from general practice to a rheumatology clinic. Br Y Rheumatol 1988; 27: 74-6.

12 Wilkin D, Smith A. Explaining variation in general practitioner referrals to hospital. Family Practice 1987; 4:160-9.

13 Secretaries of State for Health, Wales, Northern Ireland and Scotland. Working for Patients. London: HMSO, 1989 (Cmnd 555).

14 Haslock I. Working for patients? Br f Rheumatol 1989; 28: 185-6.

\section{International conferences: Are they any use?}

The gluttons for punishment who enjoy international conferences will be delighted to learn that of 327 members of the British Society for Rheumatology who replied to a questionnaire about them, $89 \%$ wished to see their continuation, though only $53 \%$ went regularly to such conferences. Few would doubt the value of small groups from different disciplines meeting to discuss a narrowly defined subject. The scientific content of the bigger gatherings was not rated highly (only 16\%), though only $15 \%$ thought they were completely useless. Educational aspects fared a little better, in that $90 \%$ thought there was value in these, but again only $17 \%$ rated this feature highly. The American Rheumatism Association meetings were held up as a model of excellence for their educational update. Perceived value of international conferences was in the opportunity to meet people- $-74 \%$ valued this highly, and only one lone soul felt it to be useless. Rheumatologists rightly feel that there is no substitute for personal contact in discussions, and it is a pleasure to put names to faces.
Mrs Currey (the politician not the rheumatologist) will be pleaseci to learn that $41 \%$ of attenders take their spouses, thus diminishing the temptation of the fleshpots of many free-wheeling conferences. One respondent uttered the plaintive cry, 'She won't come'. The alternative, as I once experienced in a workshop organised by a pharmaceutical company, is to lock up the participants in a remote castle. We were allowed to walk in the grounds between sessions!

It was apparent that the basic scientists were disadvantaged in their ability to attend such conferences-always assuming one does regard it as a disadvantage. The opportunity to listen and talk to colleagues from one's own and different countries was felt to be valuable for single handed consultants without help at senior registrar grade. They have few opportunities to discuss problems, share their own experience, and learn from others. Such isolation may not be appreciated by those working in teaching centres with a smaller workload (presumably the respondent was referring to London). 